\title{
Smart Grid Architecture Model - India and Germany
}

\section{Sasikumar, S. Jaganthan, Ragvan T}

\begin{abstract}
The smart grid is transformation method for out-of-date electric allocation system, smart grid is a fresh solution of upcoming infrastructure. It is used to Shield, scrutinize and auto optimize the electric operations from very high voltage network to disseminated structure. The smart grid is a grouping of information and the communication knowledge, transmission and distribution system. The standing traditional grid wasfurther down pressure and challengedvaried issues. There are many modifications between smart and traditional grids such as two way operations instead of one way operations, computational intellect, self-monitoring abilities, cyber protected communication, safe, cost-effective environment. Number of various literatures discussed the positive topographiesof smart grid for power systems. In this paper deliberated about the evaluation about Grid Architecture typicalfinished the Function Layers mapped on Zones and domains.
\end{abstract}

Keywords-Smart Grid; Structures; NIST;Smart Grid Architectural Model

\section{INTRODUCTION}

The detail debate of smart grid aids, it is significant to discuss thesmart grid tools implications in the different countries. The significant point is that the simple layout and topologyof smart grid matched with grid traditional systems. To clarifying this argument, there is a need to inspect some design suggestions for these technologies. The smart grid system presented digital metering with two-way communications abilities. These digital meters have capable remotely operation to control voltage and current with highestclarity waveforms, real-time tariff rate structures. Furthermore, these new meters are positioned in same traditional meter places without any design consequences. In addition, smart meters have more data for handling and lead to well-organized asset management operations. The different review chapter in this article are listed

\section{INTEROPERABILITY}

A noticeable definition defines interoperability as the capability of two or more devices from the equivalent vendor, or different vendors, to interchange information and use that information for correct co-operation [IEC618502010]. The assimilation of renewable power sources arises issues in the established system and has to integrate the consumer needs.

Revised Manuscript Received on 14 August, 2019.

Mr.C.Sasikumar, Assistant Professor/Dept. of EEE, Kumaraguru College of Technology,Coimbatore, Tamilnadu, India.(Email: sasikumar.c.eee@kct.ac.in)

Dr.S. Jaganthan, Professor/ Dept. of EEE,Dr. NGP Institute of Technology,Coimbatore, Tamilnadu, India.(Email: jaganathangct@kct.ac.in)

Mr.Ragvan T, UG Scholar/Dept. of EEE, Kumaraguru College of Technology,Coimbatore, Tamilnadu, India.(Email: ragavan.15ee@kct.ac.in)

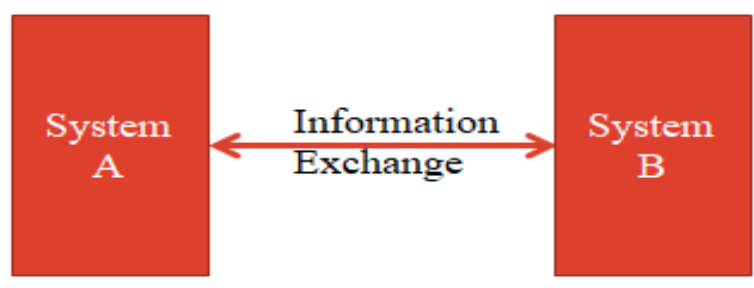

\section{A. Initial Solution}

- Transformation of primary traditional grid to smart grid structures.

- Second step ahead of integration of decentralize power generation and its resulting load pattern.

- Climate Legislation (CO2)

- Changing in Generation, Transmission and Distribution and consumer to Prosumer.

- Increase the new market participants.

\section{B. Importance Of Consumer}

Customers are the center of the transition towards smart grids

- Consumer becomes prosumer and add the part of value chain.

- Increase the level and size of market power and Net-Social Benefit.

\section{Different Structure}

The main need for a proper Smart Grid architecture that allows managing the new challenges

- Different Drivers for the introduction of Smart Grid

- Different issues depending on geographical, economical and social factors

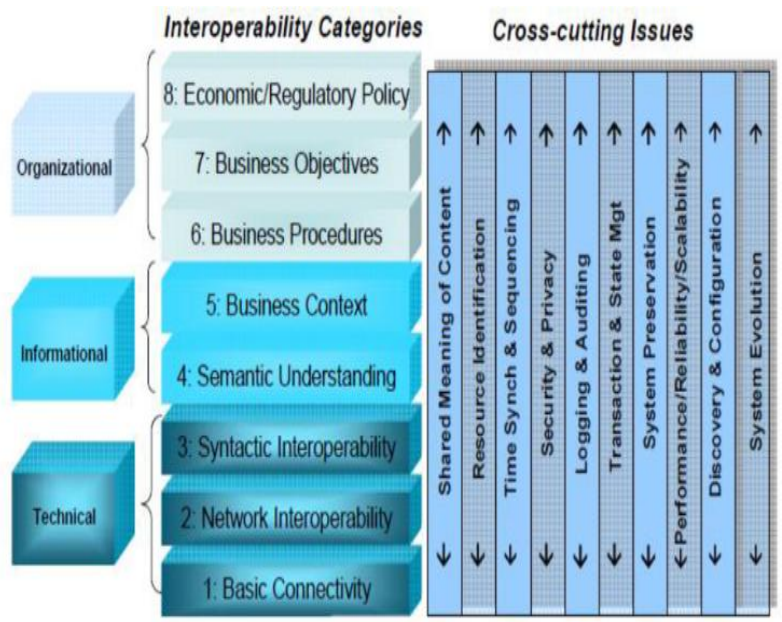

Source : GWAC2008

FIG 2 : Interoperability Categories And CrossCutting Issues 


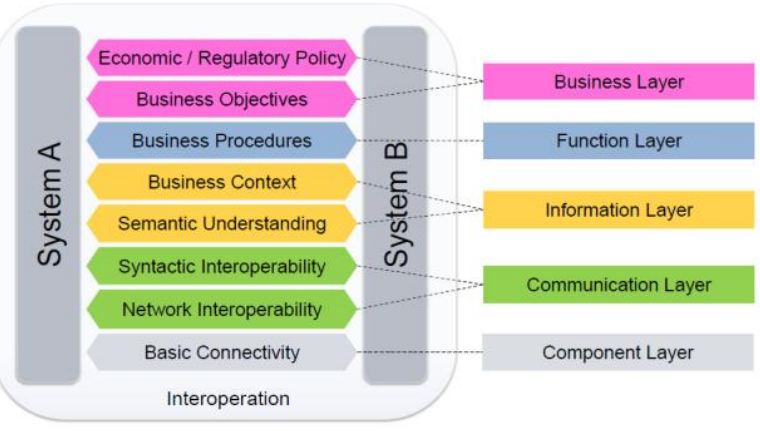

\section{Source : GWAC2008}

\section{SMART GRID ARCHITECTURE MODEL}

Mainly the country differ in economy due to geographical reasons based on that SGAM Model will be different requirments. The Main Motivation is to reprocess as much of the existing work as possible ways and not re-invent the wheel.

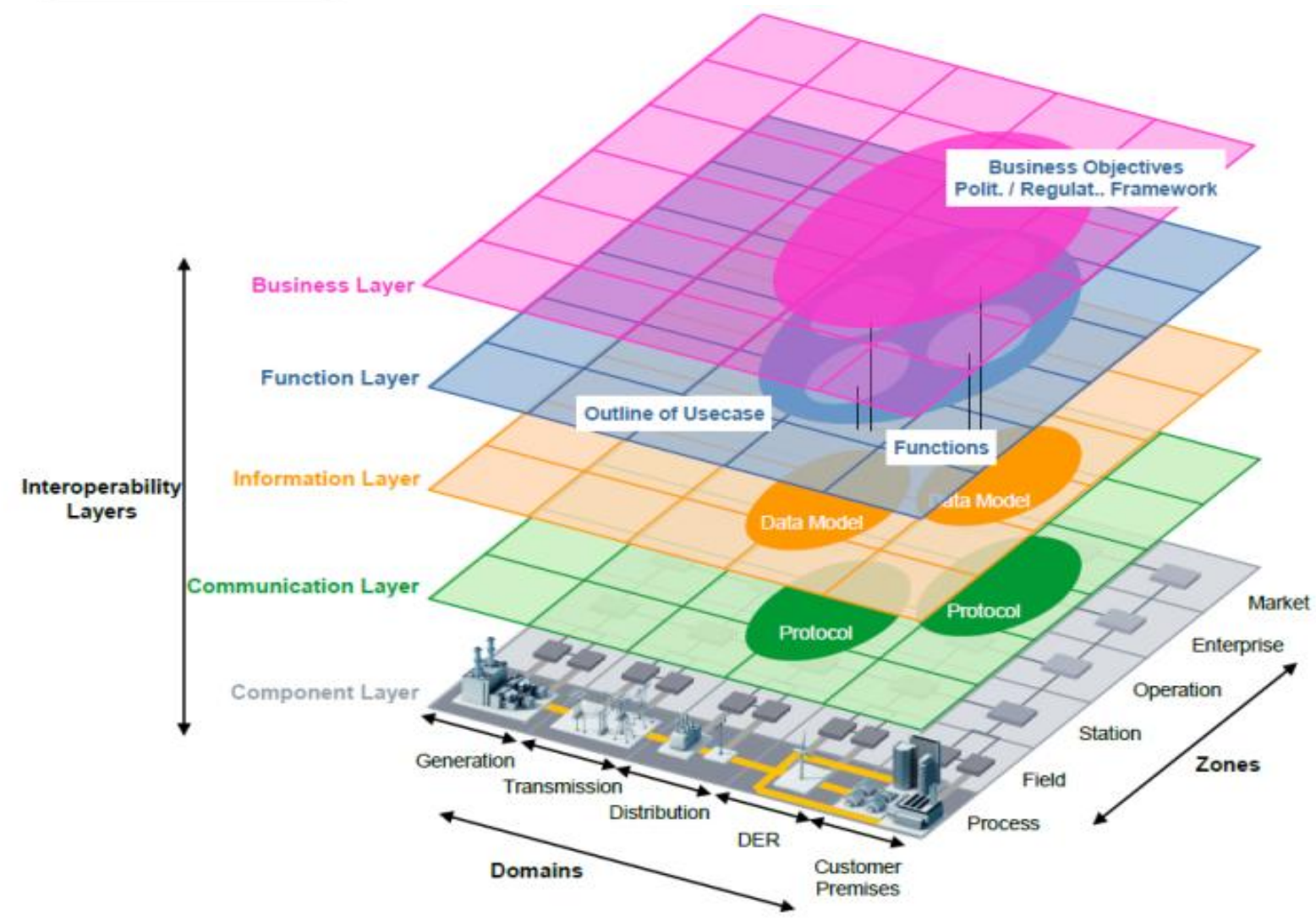

\section{A. Business Layer}

- Business view on the information exchange

- To map supervisory and economic (market) Structures

- $\quad$ It cares business administrators in decision making associated to (new) commercial models

\section{B. Function Layer}

- Describes role functions and services

- Derivative by extracting the use situation functionality which is autonomous from actors

\section{Information Layer}

Information that is being used and switched between functions, services and components.

\section{Communication Layer}

Protocols and mechanisms for the interoperable discussion of information among components

\section{E. Component Layer}

- physical distribution of all contributing components equipment

includes system actors, applications, power system

\section{FUNCTION LAYERS MAPPED ON DOMAINS AND ZONES\& RESULTS}

Common Architecture model is used to model and develop the smart grid and evolved new extended model at different condition and locality

Smart grid Conceptual Model :

National Institute of Standards and Technology

(NIST) (NIST) model.

- $\quad$ NIST extended European model (EU).

Reference Architecture :

- $\quad$ Smart Grid Architectural Model (SGAM).

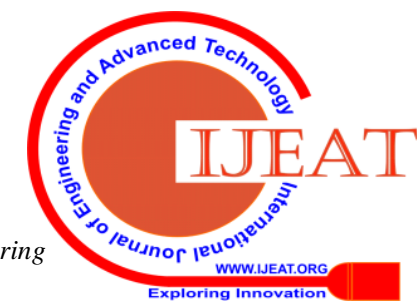




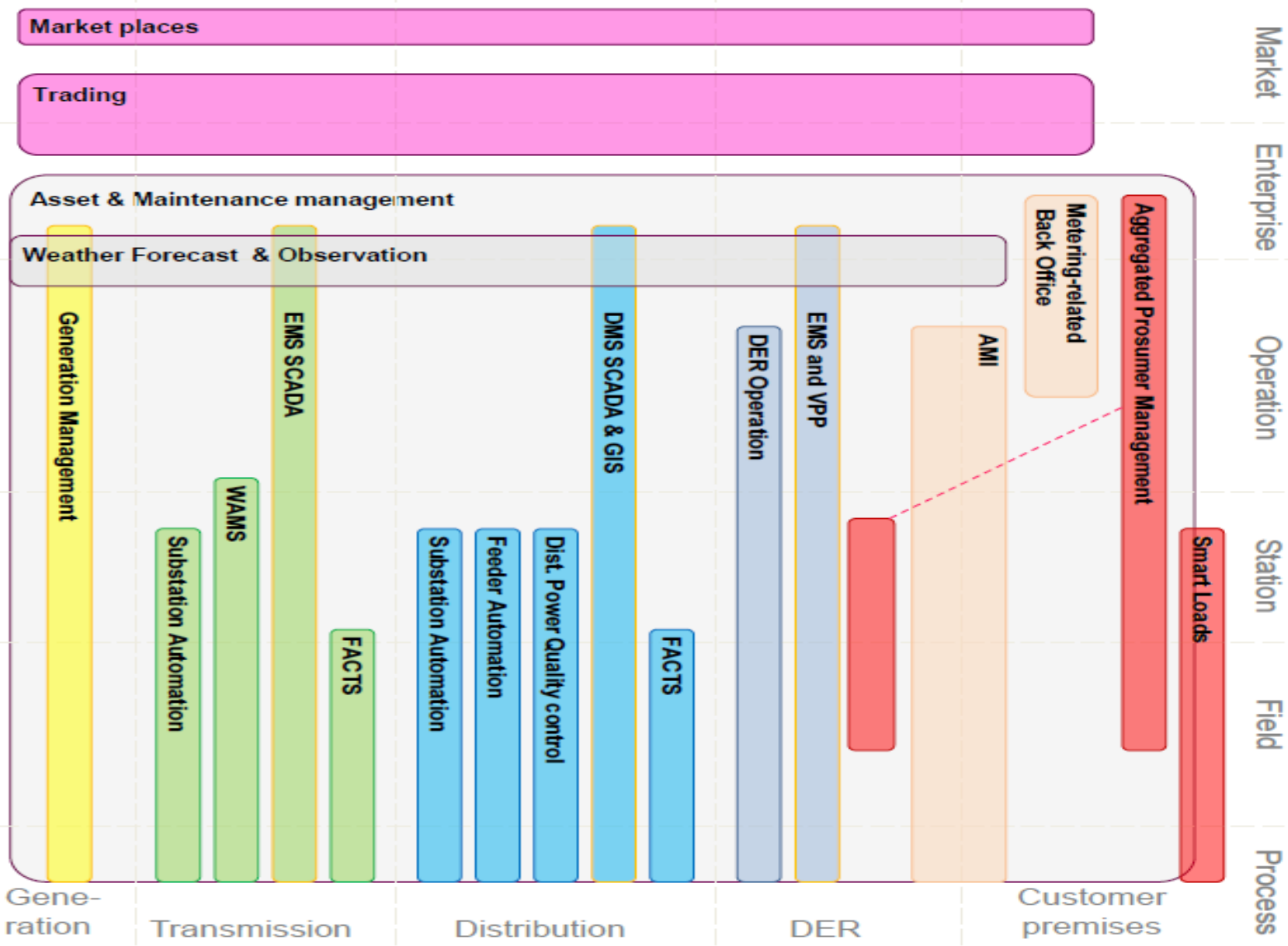

Fig 4 : Overview on Smart Grid function groups derived from Smart Grid Systems [1]

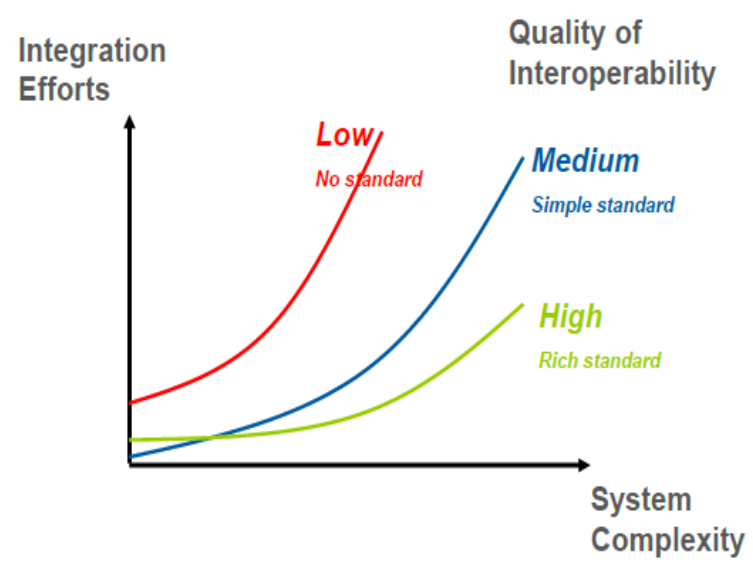

Fig 5 : Quality of Interoperability

\section{CONCLUSION}

SGAM requirements for the smart grid evolution with the constant increase in population growth, especially in the developing world, the operation of improved smart grid areimportant in the ever-increasing world population growth.SGAM is a general smart grid architecture and can be adjusted to fulfill the individual needs. Germany and India differ in geographical, technical and political systems. In future research need to development of a individual structure for Germany and India and Focus of the model has to be the consumer and economic analysis.

\section{REFERENCES}

1. Security in Critical Infrastructures Today, Proceedings of International ETG-Congress 2013; Symposium 1 (2013). Place of publication not identified: publisher not identified. Online verfügbarunter .

2. Bayindir, Ramazan; Hossain, Eklas; Vadi, Seyfettin (2016): The path of the smart grid -the new and improved power grid. In: 2016 International Smart Grid Workshop and Certificate Program (ISGWCP). Mar 21-25, 2016, Istanbul, Turkey. 2016 International Smart Grid Workshop and Certificate Program (ISGWCP). Istanbul, Turkey. ISGWCP; International Smart Grid Workshop and Certificate Program. [Piscataway, NJ], [Piscataway, NJ]: IEEE, S. 1-8.

3. cmckerracher: Drivers smart Grid India Germany.

4. EnergietechnischeGesellschaft; Internationaler ETGKongress (2013): German Smart Metering and European Privacy Needs. Energieversorgung auf demWegnach2050 ;Beiträge des Internationalen ETGKongressesvom 5. - 6. November 2013 in Berlin. Berlin: VDE-Verl. (ETG-Fachbericht, 139).

5. Fang, Xi; Misra, Satyajayant; Xue, Guoliang; Yang, Dejun (2012): Smart Grid — The New and Improved Power Grid. A Survey. In: IEEE Commun. Surv. Tutorials 14 (4), S. 944-980. DOI: 10.1109/SURV.2011.101911.00087. 
6. IEEE India International Conference on Power Electronics; Institute of Electrical and Electronics Engineers; Thapar University; India International Conference on Power Electronics; IICPE (2016): 7th IEEE India International Conference on Power Electronics. IICPE 2016 : November 17-19, 2016. 2016 7th India International Conference on Power Electronics (IICPE). Patiala, India. Piscataway, NJ: IEEE.

7. Sethuramalingam, T.K. and Nagaraj, B., 2016. A proposed system of ship trajectory control using particle swarm optimization. Procedia Computer Science, 87, pp.294-299.

8. ISGWCP; International Smart Grid Workshop and Certificate Program (2016): 2016 International Smart Grid Workshop and Certificate Program (ISGWCP). Mar 21-25, 2016, Istanbul, Turkey. 2016 International Smart Grid Workshop and Certificate Program (ISGWCP). Istanbul, Turkey. [Piscataway, NJ], [Piscataway, NJ]: IEEE.

9. Kumar, Deepak; Singh, Harvinder; Reshma (2016): A review on industry challenges in smart grid implementation. In: 7th IEEE India International Conference on Power Electronics. IICPE 2016 : November 17-19, 2016. 2016 7th India International Conference on Power Electronics (IICPE). Patiala, India. IEEE India International Conference on Power Electronics; Institute of Electrical and Electronics Engineers; Thapar University; India International Conference on Power Electronics; IICPE. Piscataway, NJ: IEEE, S. 1-5.

10. Li, Fangxing; Qiao, Wei; Sun, Hongbin; Wan, Hui Wang, Jianhui; Xia, Yan et al. (2010): Smart Transmission Grid. Vision and Framework. In: IEEE Trans. Smart Grid 1 (2), S. 168-177. DOI: 10.1109/TSG.2010.2053726.

11. McDaniel, Patrick; McLaughlin, Stephen (2009): Security and Privacy Challenges in the Smart Grid. In: IEEE Secur. Privacy Mag. 7 (3), S. 75-77. DOI: 10.1109/MSP.2009.76.

12. Vineetha, C. P.; Babu, C. A. (2014): Smart grid challenges, issues and solutions. In: The 1st International Conference on Intelligent Green Building and Smart Grid (IGBSG 2014). April 23-25, 2014. UnterMitarbeit von San-Liang Lee. 2014 International Conference on Intelligent Green Building and Smart Grid (IGBSG). Taipei, Taiwan. International Conference on Intelligent Green Building and Smart Grid; Guoli-Taiwan-KejiDaxue; IGBSG. Piscataway, NJ: IEEE, S. 1-4.

13. Sun Joo AHN (2015): Understanding Energy Challenges in India: IEA.

14. The Balance: What Defines 'Developing Countries'? Online verfügbarunter https://www.thebalance.com/what-is-a-developingcountry-1978982, zuletztgeprüft am 06.03.2018. 